\title{
Palliative Procedures for Transposition of the Great Arteries
}

\author{
HAMISH WATSON
}

Transposition of the great arteries is the most frequent cause of cyanotic heart disease in the newborn, and accounts for some 8-10 per cent of all congenital cardiac malformations. Until recently, however, it was comparatively rare in older patients because most babies with this lesion have circulations that are barely compatible with extrauterine life, and they survived for no more than a few weeks or months. Those who did not die of heart failure in infancy were a small self-selected group, and few physicians outside very large centres had much experience in their management or opportunity to study their natural history in meaningful numbers.

Though this state of affairs has constituted a considerable surgical challenge for many years, the problems presented by transposition have taken longer to solve than those of other common lesions: not only because of the seemingly insurmountable obstacle of the coronary arterial blood supply, but also because of the special technical and biochemical difficulties inherent in the cardiac surgery of cyanosed babies with failing hearts.

Blalock and Hanlon (1950) were the first to tackle the problem with any success. They noted that the patients who survived longest had defective septa or persistence of the ductus arteriosus, and found that it was technically possible to fashion an artificial ductus, transpose a portion of the venous return, or create an atrial septal defect in the laboratory (Blalock and Hanlon, 1948; Hanlon and Blalock, 1948). Despite the fact that they had been unable to keep any of their experimental animals with artificially transposed great arteries alive in this way, they decided to give such measures a clinical trial because the prognosis was so bad that any method offering reasonable hope of improvement seemed justified. Early in 1948 they began to operate upon a series of 33 of Helen Taussig's patients, 14 of whom were less than 10 months old and whose ages ranged from 8 days to 8 years. Of the first 10, 9 had venous or atrial extracardiac shunts constructed, and they all died: 1 during the operation and the rest within a few minutes or days of its completion. Most of them had terminal pulmonary oedema thought to be due to an upset in the balance between the two circulations resulting from unidirectional flow through the anastomosed vessels. Because of this experience they decided that out-of-phase bidirectional shunting was desirable, and this they achieved by creating an atrial septal defect, the procedure now known as the Blalock Hanlon operation. Of the 12 patients so treated, 9 died soon after, but 3 survived; 1 aged 8 months, another aged 14 months, and the third aged $2 \frac{1}{2}$ years. All seemed improved, though the improvement was not dramatic, and so the next 12 patients had a right subclavian-pulmonary artery anastomosis created at the same time as the atrial septal defect, and 8 survived. This time, however, the children were also significantly older, the youngest being 2 and the average age being $4 \frac{1}{2}$ years. The best result was in a 7-year-old girl who had pulmonary stenosis as an additional lesion, and they wondered, almost 20 years ago, if it might not therefore be a good idea to constrict the pulmonary artery before other operative treatment for transposition.

Blalock was obviously not pleased with the modest improvement in these patients. It did not compare with the results he had obtained in Fallot's tetralogy, and he made the point that with arterial oxygen saturations of less than 75 per cent, the stimulus to polycythaemia persisted, and in some cases the red blood count actually increased after successful surgical treatment. He envisaged direct realignment of the great arteries, later tried unsuccessfully by Bailey et al. (1954), Mustard et al. (1954), Senning (1959), and Idriss et al. (1961), or that a similar result might be achieved by crisscross grafts, which were tried without success by Björk and Bouckaert (1954) and Kay and Cross (1955).

Meantime the problem of correction was being tackled by redirection of venous input rather than 
by rearrangement of arterial output. After Albert (1954) had reported that flaps of the interatrial septum could be used to redirect venous return in dogs, many ingenious though unsuccessful attempts to do this in children were described, most of which used some sort of interatrial prosthesis (Kay and Cross, 1957; Merendino et al., 1957; Creech et al., 1958; Glotzer, Bloomberg, and Hurwitt, 1960; Shumacker, 1961; Wilson et al., 1962). Reading them now, it is clear that the patients did not survive what were in many cases technically successful operations because they were too young for the preand post-operative care, and too small for the methods of perfusion that were then available. In fact, they high-lighted the dilemma of those treating transposition-that too few lived long enough to give the surgeons much chance of operating upon reasonably sized patients.

Such failures, however, emphasized the need for a good palliative procedure, and with an untreated neonatal mortality rate of more than 90 per cent there has been no lack of interest (Lillehei and Varco, 1953; Murphy et al., 1955; Baffes, 1956; Baffes et al., 1957; Glenn, 1958; Moss, Maloney, and Adams, 1961; Ochsner et al., 1961; Schuster et al., 1963; Trusler, Mustard, and Fowler, 1964; Edwards and Bargeron, 1965; Lindesmith et al., 1965). As Baffes said when introducing his technique at the 37th Annual Meeting of the American Association for Thoracic Surgery in 1957, "evolution of the surgical correction of transposition has been difficult and tedious. Hardly a major cardiovascular group exists which has not had one or more of its members devote a great deal of time and energy in that direction". His operation, designed to divert systemic venous return from the inferior vena cava to the left atrium, and pulmonary venous return from the right superior pulmonary veins to the right atrium, was very successful in his own hands. Starting in 1955, 117 patients whose ages ranged from 6 days to 15 years were treated, with an over-all mortality rate of 29 per cent (Baffes et al., 1960). Most people favoured the Blalock Hanlon type of operation, however, which created an atrial septal defect; and Cooley, describing 6 years' experience of his modification of this procedure in 45 cases, most of whom were less than 1 year old and half less than 3 months old, reported that 82 per cent of the last 28 patients had survived (Ochsner et al., 1961).

These, though splendid results, were misleading figures because few could approach them in tiny children, and in most hands the operative mortality in infancy, where the need was greatest, was almost prohibitive. Even in more recently published series the operative mortality remained high, varying between 25 and 58 per cent (Starr et al., 1964; Trusler et al., 1964; Lindesmith et al., 1965; Reed, 1965; Waterston, 1965; Cornell et al., 1966; Nauta, Van Der Schaar, and Brom, 1966; Venables, 1966); and there is no doubt that many babies also died while awaiting or being prepared for surgical treatment (Venables, 1966).

It is against such high mortality, treated or untreated, that the introduction of atrial septostomy should be viewed (Rashkind and Miller, 1966). This relatively simple procedure, which can be carried out with a balloon during diagnostic cardiac catheterization even in the smallest and illest of babies who would seldom survive operation, has transformed the outlook for those born with transposition. It has not only solved the first part of the twofold surgical problem-how to keep the majority of them alive until they are old enough and in sufficiently good shape to tolerate the surgical, biochemical, and respiratory hazards of opening the chest and heart (Watson and Rashkind, 1967)-but also, by ensuring that a vastly larger number of patients with transposition are available, has helped the surgeons solve the second-how best to correct the malformation.

The rapidity with which Rashkind's life-saving procedure has been adopted by nearly every cardiovascular centre in the world is proof of its efficiency, and in a remarkably short period it has established itself as possibly the greatest advance so far made in the treatment of serious cyanotic congenital heart disease in the newborn.

Though Rashkind and Miller (1968) have reported success in older children aged $2,3,6,8$, and 12 years, septostomy becomes increasingly difficult as the child gets older. After the first year of life the balloon usually ruptures before the septum. This has been the author's experience in 3 patients aged 11,13 , and 15 months, and several personal communications have told of similar experiences where it has been necessary to revert to a Blalock Hanlon type operation because of failed or inadequate septostomy.

The exact role of the balloon catheter in the management of patients with transposed great arteries is therefore not yet clear. Of its superiority over other palliative procedures in babies there can be no doubt; but older infants and small children, who are in any case a self-selected group of survivors, present a different problem. Most of those who survive for $\mathbf{6}$ months or more are in no immediate danger, and further experience is required to decide between open and closed septostomy. Whatever their relative merits, the balloon catheter arrived on the scene at a most appropriate time when the efforts of those who had persevered with 
more radical surgical treatment were beginning to be rewarded.

Senning (1959) was the first to report success: a 9-year-old boy, one of four patients in whom the interatrial septum and part of the posterior wall of the right atrium were used to redirect systemic and pulmonary venous return. Others using this technique soon followed: Kirklin, Devloo, and Weidman (1961) had 4 survivors, 3 of whom were small (3 months, 12 months, and 13 months), out of 11 patients; Aronstam et al. (1963) had one in a child aged 16 months; and Helmsworth et al. (1964) described a successful repair in a 10-week-old baby. Barnard, Schrire, and Beck (1962) used a Teflon tube to bring the pulmonary venous return to the tricuspid valve in a 16-year-old boy, but the use of prostheses was not generally favoured. Many also thought that Senning's original technique tended partially to obstruct venous return to the heart, and the operation described by Mustard (1964), in which a pericardial baffle is used to direct flow from the great veins entering the heart to the appropriate atrioventricular valves, has been the method of choice in recently reported series of successful corrections (Mustard et al., 1964; Aberdeen et al., 1965; Cooley et al., 1966; Hightower, Weidman, and Kirklin, 1966).

The immediate results for those with uncomplicated transpositions are most encouraging, and post-operative haemodynamic studies have shown that it is possible to restore normal cardiac function (Kidd and Mustard, 1966). While it is tempting to talk of "correction", it should be remembered that only the venous return has been corrected, and that whether or not this is a truly corrective or yet another, albeit highly successful, palliative procedure depends largely upon whether or not the right ventricle can maintain a systemic work load for a normal life span. It had been thought that subtle differences between the ventricles fitted them for their respective high and low pressure loads, but Shah and Kidd (1966) have shown that where the peak systemic pressure relations are reversed, the peak dp/dt ratios are also reversed-suggesting that they are related to function and not predetermined by embryological or anatomical factors. Be that as it may, experience of patients with other lesions where the right ventricle has to pump at systemic pressure against a high resistance, either in the pulmonary vascular bed or because of outflow obstruction, has shown that they have a greatly shortened expectation of life. While it is true that in these conditions the resistance tends to increase with age, it is probable that a ventricle's blood supply ultimately determines its working capacity.
The anatomy of the coronary arteries in transposition is complex and varied (Rowlatt, 1962; Elliot, Amplatz, and Edwards, 1966; Shaher and Puddu, 1966), but in up to one-third of cases either the left circumflex or the anterior descending branch arises from the right coronary artery. If this means that the right ventricle has a left ventricular-like blood supply, it may well be that under such circumstances it can function as the systemic ventricle for an indefinite period. Time will tell; but for the majority it seems at least possible that redirection of venous return is not truly corrective and that definitive treatment must still entail realignment of the great arteries. Time, however, has also been purchased by the techniques of Rashkind and Mustard, and if further correction is required, increasing experiences of coronary arterial surgery will make this less hazardous, so that operations of the type described by Potts and his associates (Idriss et al., 1961) might well be successful.

That palliative procedures work is witnessed by the fact that children with transposition, once few and far between at follow-up clinics, now turn up in steadily increasing numbers. Their management has become a matter of daily concern rather than one of occasional academic interest. Haemodynamic studies before and after successful operations (Hastreiter et al., 1966; Shaher and Kidd, 1966) and balloon septostomy (Rashkind and Miller, 1968) have confirmed that their future depends largely upon the nature and severity of additional congenital cardiac malformations.

Less than 50 per cent of cases have uncomplicated lesions; that is, transposed great arteries, two ventricles, and intact septa or only a small foramen ovale defect. In the rest, every type of lesion may be found, and some very complex hearts are encountered-especially in the group with situs inversus or asplenia (Paul, Van Praagh, and Van Praagh, 1968), which until recently were merely problems for the pathologist with a special interest. For practical purposes, however, ventricular septal defect is by far and away the most important and is present in at least 40 per cent of all cases. Though a defective interventricular septum greatly increases the chances of survival in infancy, particularly if the ductus has closed (Keith, Rowe, and Vlad, 1967), it certainly complicates the problem after successful septostomy; not only so far as immediate management is concerned, but also in planning future operations. Babies with transposition depend upon out-of-phase bidirectional shunting for survival, and in a few cases the creation of a large defect in the atrial septum may so upset the delicate balance between previously existing shunts at ventricular and ductal level, particularly if the ductus 
persists, that surgical intervention is required to reduce their significance.

In the post-Rashkind era, when babies with transposition should not die, the main problem posed by the large numbers with ventricular septal defects, however, is not heart failure but the prevention of pulmonary vascular disease, which all are agreed makes future correction dangerous or impossible. A significant and fortunate number, possibly 15-20 per cent of those with ventricular septal defect also have pulmonary stenosis, which protects their pulmonary vascular bed from the effects of increased flow. There is accumulating evidence that all such lesions may not have been present since birth, and acquired obstruction in the left ventricular outflow tract, though of considerable interest, was predictable in view of the fibromuscular continuity that exists between the pulmonary and mitral valves, and the left ventricle in most transposition complexes.

If the blood flow to the lungs is seriously diminished by pulmonary stenosis, a palliative procedure of the Blalock or Waterston type can be used to increase it, but opinions seem divided about the advisability of such operations when the great arteries are transposed. Blalock and Hanlon claimed that the best results were obtained when an aorto-pulmonary shunt was created at the same time as an atrial septal defect; Baffes found that it increased his mortality rate from 29 to 50 per cent and lessened the chance of improvement in the survivors. For the majority, pulmonary stenosis can probably be regarded as a naturally occurring palliative procedure in infancy, and only becomes a serious problem when the time comes for total surgical correction.

Those with significant ventricular septal defects whose lungs are not protected from increased flow are the most difficult cases to manage. There is evidence that pulmonary arteriolar change may take place with alarming rapidity in this group, and banding of the pulmonary artery (Muller and Dammann, 1952) may be required as a further palliative procedure to protect the lung vessels from permanent damage.

The importance of the pulmonary vascular bed in determining the ultimate fate in many forms of congenital heart disease (Dammann and Ferencz, 1956) is now fairly widely appreciated, but much more experience and better correlation between clinical, haemodynamic, and histological data are required to unravel the complexities of the various types of pulmonary hypertension (Brit. med. $\mathcal{F}$., 1969).

Nowhere is the situation more complex than in transposition of the great arteries. Ferguson,
Adams, and Watson (1960), who studied the lungs of 68 infants who had died from transposition, found that the pulmonary arterioles retained their thick muscular structure for about three months after birth, during which time the vessels of normal controls showed rapid thinning, and that thereafter further thickening developed. This was a general conclusion and no differentiation was made between the 39 cases who had ventricular septal defects and the 29 who did not. Ferencz (1966), who had made careful and extensive studies of the pulmonary vessels in 106 specimens with transposition $60 \%$ under 6 months, $72 \%$ under 1 year, and $85 \%$ under 2 years), also found medial hypertrophy, either alone or in combination with intimal fibrosis, in nearly all cases. She excluded all hearts whose basic design, apart from transposition, was abnormal, and found little difference except one of degree between the arteriolar changes in those with an intact ventricular septum and those with large ventricular septal defects. These striking and severe changes were interpreted as evidence of a high resistance to flow through the pulmonary arteriolar bed, and were taken to indicate the urgency of early surgery.

Why those without ventricular defects should have severe and progressive pulmonary vascular disease is difficult to understand. Astley and Parsons (1952) believed that persistence of the ductus was associated with a poor prognosis, and more recently Reed, Lauer, and Diehl (1966) have suggested that the ductus should always be ligated, even when the ventricular septum is intact, because a large flow through it may damage the lungs. In a few cases the ductus may be incriminated; in the majority, however, it is hard to believe that such changes as those described by Ferguson and his colleagues, and by Ferencz could possibly arise without increased flow.

It is suggested that increased pulmonary blood flow is present in transposition even in the absence of significant shunts, but great care is required when interpreting the evidence for this. Overfilled lung fields do not necessarily signify rapid flow, and Burchell (1966) has rightly drawn attention to the difficulties and possible fallacies inherent in calculating pulmonary blood flow by ordinarily accepted methods when the pulmonary and systemic circuits are in parallel rather than in series. Significantly too, he has questioned whether such pathological changes in the lung vessels of those who have died are in any way representative of the state of affairs in those who survive. Significantly, because two recent and important publications-one a painstaking haemodynamic study on a carefully selected and accurately diagnosed group of patients, 
the other a histological study of pulmonary vessels obtained by biopsy rather than at necropsy-have confirmed the wisdom of this editorial comment.

To study the effect of ventricular septal defect and persistence of the ductus arteriosus on left ventricular pressures in complete transposition of the great arteries, Shaher and Kidd (1968) used rigid criteria to select 80 children, 37 of whom had a ventricular septal defect, 22 an intact ventricular septum with a persistent ductus arteriosus, and 21 an intact ventricular septum with no persistent ductus. They found that $\mathbf{9 2}$ per cent of those with ventricular septal defects and 45 per cent of those with persistent ductus, but only 5 per cent of those with neither, had left ventricular pressures greater than $\mathbf{7 0}$ per cent of the systemic pressure. Furthermore, in 76 per cent of the children with neither ventricular septal defects nor persistent ductus, the left ventricular pressure was only between 20 and 40 per cent of that in the systemic circuit.

To study the histological picture of the small muscular pulmonary arteries in live children with transposition, Wagenvoort et al. (1968) examined specimens of lung taken for biopsy from 80 patients during surgical operations. They found that in 31 patients with an intact ventricular septum (haemodynamically similar to Shaher and Kidd's) the media of pulmonary arteries was generally thinner than normal and the lumina widely patent. This was especially marked where the haematocrit was high, and suggested that the dilatation was consequent upon increased blood volume. Intimal fibrosis was present in only 7 subjects in this group. It was slight, patchy, and suggestive of organized thrombus. In striking contrast was a group of 28 patients with ventricular septal defect whose right and left ventricular pressures were equal, and whose pulmonary arterioles showed marked medial hypertrophy with concentric intimal proliferation. When pulmonary stenosis was present, the vessels had atrophic media; and intimal fibrosis based upon thrombotic lesions was regularly present.

The results of these studies are in keeping with what might have been expected from experience with other types of congenital cardiac malformation and, if confirmed, are of obvious importance when considering the timing and nature of palliative operations in transposition. Clearly those with large ventricular septal defects are at greatest risk, and banding of the pulmonary artery is required to protect their lungs until the defect is closed, though its timing may depend to some extent upon whether it is an elective procedure designed to prevent vascular lesions or an emergency one required to relieve heart failure.

Successful palliative procedures do not solve all the problems posed by transposition of the great arteries, nor do they protect those who survive them from other hazards, such as cerebral vascular accidents, bacterial endocarditis, and brain abscess, to which all patients with cyanotic congenital heart disease are exposed. They do, however, prevent heart failure and early death; and whatever the future may hold for those born with this once apparently incurable malformation, their expectation of life is already so much better than appeared possible only a few years ago, that the remaining problems now seem certain of solution.

\section{REFERENCES}

Aberdeen, E., Waterston, D. J., Carr, I., Graham, G., Bonham-Carter, R. E., and Subramanian, S. (1965). Successful "correction" of transposed great arteries by Mustard's operation. Lancet, 1, 1233.

Albert, H. M. (1954). Surgical correction of transposition of the great vessels. Surg. Forum, 5, 74.

Aronstam, E. M., Hewlett, T. H., Orbison, J. A., Franklin, R. B., and Dixon, L. M. (1963). Surgical correction of transposition of the great vessels: a successful complete correction. Ann. Surg., 158, 282.

Astley, R., and Parsons, C. (1952). Complete transposition of the great vessels. Brit. Heart F., 14, 13.

Baffes, T. G. (1956). A new method for surgical correction of transposition of the aorta and pulmonary artery. Surg. Gynec. Obstet., 102, 227.

—, Lev, M., Paul, M. H., Miller, R. A., Riker, W. L., De Boer, A., and Potts, W. J. (1960). Surgical correction of transposition of the great vessels: a five-year survey. F. thorac. cardiovasc. Surg., 40, 298.

-, Riker, W. L., De Boer, A., and Potts, W. J. (1957). Surgical correction of transposition of the aorta and the pulmonary artery. F. thorac. Surg., 34, 469.

Bailey, C. P., Cookson, B. A., Downing, D. F., and Neptune, W. B. (1954). Cardiac surgery under hypothermia. f. thorac. Surg., 27, 73.

Barnard, C. N., Schrire, V., and Beck, W. (1962). Complete transposition of the great vessels: a successful complete correction. F. thorac. cardiovasc. Surg., 43, 768.

Björk, V. O., and Bouckaert, L. (1954). Complete transposition of the aorta and the pulmonary artery. An experimental study of the surgical possibilities for its treatment. f. thorac. Surg., $28,632$.

Blalock, A., and Hanlon, C. R. (1948). Interatrial septal defect-its experimental production under direct vision without interruption of the circulation. Surg. Gynec. Obstet., 87, 183.

- and $-(1950)$. The surgical treatment of complete transposition of the aorta and the pulmonary artery. Surg. Gynec. Obstet., 90, 1.

Brit. med. f. (1969). Leading article. Reversibility of pulmonary hypertension. 1, 201.

Burchell, H. B. (1966). Some hemodynamic problems in transposition of the great vessels: Editorial. Circulation, 33, 181.

Cooley, D. A., Hallman, G. L., Bloodwell, R. D., and Leachman, R. D. (1966). Two-stage surgical treatment of complete transposition of the great vessels. Arch. Surg., 93, 704.

Cornell, W. P., Maxwell, R. E., Haller, J. A., and Sabiston, D. C. (1966). Results of the Blalock-Hanlon operation in 90 patients with transposition of the great vessels. f. thorac cardiovasc. Surg., 52, 525. 
Creech, O., Jr., Mahaffey, D. E., Sayegh, S. F., and Sailors, E. L. (1958). Complete transposition of the great vessels; a technique for intracardiac correction. Surgery, 43, 349.

Dammann, J. F., and Ferencz, C. (1956). The significance of the pulmonary vascular bed in congenital heart disease. Amer. Heart f., 52, 7.

Edwards, W. S., and Bargeron, L. M., Jr. (1965). More effective palliation of transposition of the great vessels. f. thorac. cardiovasc. Surg., 49, 790.

Elliott, L. P., Amplatz, K., and Edwards, J. E. (1966). Coronary arterial patterns in transposition complexes. Amer. F. Cardiol., 17, 362.

Ferencz, C. (1966). Transposition of the great vessels: pathophysiologic considerations based upon a study of the lungs. Circulation, 33, 232.

Ferguson, D. J., Adams, P., and Watson, D. (1960). Pulmonary arteriosclerosis in transposition of the great vessels. Amer. F. Dis. Child., 99, 653.

Glenn, W. W. L. (1958). Circulatory bypass of the right side of the heart: IV. Shunt between superior vena cava and distal right pulmonary artery-report of clinical application. New Engl. f. Med., 259, 117.

Glotzer, P., Bloomberg, A. E., and Hurwitt, E. S. (1960). An experimental procedure for correction of transposition of the great vessels. Arch. Surg., 80, 12.

Hanlon, C. R., and Blalock, A. (1948). Complete transposition of the aorta and the pulmonary artery. Experimental observations on venous shunts as corrective procedures. Ann. Surg., 127, 385.

Hastreiter, A. R., Serratto, M., Arevalo, F., and Miller, R. A. (1966). Long-term hemodynamic studies in postoperative patients with transposition of the great vessels. Results of the venous switching operation. Circulation, 33, Suppl. I, p. 34.

Helmsworth, J. A., Kaplan, S., Keirle, A. M., and Jones, D. V. (1964). Results of palliative and curative operations for transposition of aorta and pulmonary artery. Circulation, 29, Suppl. I, p. 114.

Hightower, B. M., Weidman, W. H., and Kirklin, J. W. (1966). Open intracardiac repair for complete transposition of the great arteries. Circulation, 33, Suppl. I, p. 19.

Idriss, F. S., Goldstein, I. R., Grana, L., French, D., and Potts, W. J. (1961). A new technic for complete correction of transposition of the great vessels. Circulation, 24, 5.

Kay, E. B., and Cross, F. S. (1955). Surgical treatment of transposition of the great vessels. Surgery, 38, 712 .

$\longrightarrow$, and - (1957). Transposition of the great vessels corrected by means of atrial transposition. Surgery, 41, 938.

Keith, J. D., Rowe, R. D., and Vlad, P. (1967). Heart Disease in Infancy and Childhood, 2nd ed. Macmillan, New York.

Kidd, L., and Mustard, W. T. (1966). Hemodynamic effects of a totally corrective procedure in transposition of the great vessels. Circulation, 33, Suppl. I, p. 28.

Kirklin, J. W., Devloo, R. A., and Weidman, W. H. (1961). Open intracardiac repair for transposition of the great vessels: Eleven cases. Surgery, 50, 58.

Lillehei, C. W., and Varco, R. L. (1953). Certain physiologic, pathologic, and surgical features of complete transposition of the great vessels. Surgery, 34, 376.

Lindesmith, G. G., Meyer, B. W., Jones, J. C., and Gallaher, M. (1965). Palliative procedure for treatment of transposition of the great vessels. Circulation, 31, Suppl. I, p. 21.

Merendino, K. A., Jesseph, J. D., Herron, P. W., Thomas, G. I., and Vetto, R. R. (1957). Interatrial venous transposition: a one-stage intracardiac operation for the conversion of complete transposition of the aorta and pulmonary artery to corrected transposition. Theory and clinical experience. Surgery, 42, 898.

Moss, A. J., Maloney, J. V., and Adams, F. H. (1961). Transposition of the great vessels: surgical palliation during infancy. Ann. Surg., 153, 183.

Muller, W. H., Jr., and Dammann, J. F., Jr. (1952). The treatment of certain congenital malformations of the heart by the creation of pulmonic stenosis to reduce pulmonary hypertension and excessive pulmonary blood flow: a preliminary report. Surg. Gynec. Obstet., 95, 213.

Murphy, T. O., Gott, V., Lillehei, C. W., and Varco, R. L. (1955). Results of surgical palliation in 32 patients with transposition of the great vessels. Surg. Gynec. Obstet., 101, 541.

Mustard, W. T. (1964). Successful two-stage correction of transposition of the great vessels. Surgery, 55, 469.

-, Chute, A. L., Keith, J. D., Sirek, A., Rowe, R. D., and Vlad, P. (1954). A surgical approach to transposition of the great vessels with extracorporeal circuit. Surgery, 36, 39.

—, Keith, J. D., Trusler, G. A., Fowler, R., and Kidd, L. (1964). Surgical management of transposition of the great vessels. F. thorac. cardiovasc. Surg., 48, 953.

Nauta, J. Van Der Schaar, H., and Brom, A. G. (1966). Palliative operations for transposition of the great arteries. Proc. Ass. Europ. paediat. Cardiol., 2, 11.

Ochsner, J. L., Cooley, D. A., Harris, L. C., and McNamara, D. G. (1961). Treatment of complete transposition of the great vessels with the Blalock-Hanlon operation. Circulation, 24, 51.

Paul, M. H., Van Praagh, S., and Van Praagh, R. (1968). Transposition of the great arteries. In Paediatric Cardiology, pp. 576-610. Ed. by Hamish Watson. Lloyd-Luke, London.

Rashkind, W. J., and Miller, W. W. (1966). Creation of an atrial septal defect without thoracotomy. A palliative approach to complete transposition of the great arteries. f. Amer. med. Ass., 196, 991.

- and - (1968). Transposition of the great arteries. Results of palliation by balloon atrioseptostomy in thirty-one infants. Circulation, 38, 453.

Reed, W. A. (1965). Selection of palliative operation for transposition of the great vessels. Circulation, 31, Suppl. I, p. 25.

—, Lauer, R. M., and Diehl, A. M. (1966). Staged correction of total transposition of the great vessels. Circulation, 33, Suppl. I, p. 13.

Rowlatt, U. F. (1962). Coronary artery distribution in complete transposition. F. Amer. med. Ass., 179, 269.

Schuster, S. R., Kiernan, E., Rosencranz, J., and Bozer, A. (1963). A new technique for the creation of an atrial septal defect with clinical application. $\mathcal{F}$. thorac. cardiovasc. Surg., 46, 510.

Senning, A. (1959). Surgical correction of transposition of the great vessels. Surgery, 45, 966.

Shah, P., and Kidd, L. (1966). First derivative of intraventricular pressures in complete transposition of great vessels. Brit. Heart f., 28, 712.

Shaher, R. M., and Kidd, L. (1966). Hemodynamics of complete transposition of the great vessels before and after the creation of an atrial septal defect. Circulation, 33, Suppl. I, p. 3.

$\longrightarrow$, and - (1968). Effect of ventricular septal defect and patent ductus arteriosus on left ventricular pressure in complete transposition of the great vessels. Circulation, 37, 232. 
Shaher, R. M., and Puddu, G. C. (1966). Coronary arterial anatomy in complete transposition of the great vessels. Amer. F. Cardiol., 17, 355.

Shumacker, H. B., Jr. (1961). A new operation for transposition of the great vessels. Surgery, 50, 773.

Starr, A., Campbell, T. J., Wood, J., McCord, C., Herr, R., and Menashe, V. (1964). Transposition of the great vessels: Recent experience with the Blalock-Hanlon procedure. Amer. F. Surg., 108, 198.

Trusler, G. A., Mustard, W. T., and Fowler, R. S. (1964). The role of surgery in the treatment of transposition of the great vessels. Canad. med. Ass. F., 91, 1096.

Venables, A. W. (1966). Complete transposition of the great vessels in infancy with reference to palliative surgery. Brit. Heart f., 28, 335.
Wagenvoort, C. A., Nauta, J., van der Schaar, P. J., Weeda, H. W. H., and Wagenvoort, N. (1968). The pulmonary vasculature in complete transposition of the great vessels, judged from lung biopsies. Circulation, 38, 746.

Waterston, D. J. (1965). Transposition of the great arteries. Brit. med. f., 2, 934.

Watson, H., and Rashkind, W. J. (1967). Creation of atrial septal defects by balloon catheter in babies with transposition of the great arteries. Lancet, 1, 403.

Wilson, H. E., Nafrawi, A. G., Cardozo, R. H., and Aguillon, A. (1962). Rational approach to surgery for complete transposition of the great vessels. Ann. Surg., 155, 258. 